\title{
Competition for glucose between Candida albicans and oral bacteria grown in mixed culture in a chemostat
}

\author{
N. J. BASSON
}

Oral and Dental Research Institute, Faculty of Dentistry, University of Stellenbosch, South Africa

\begin{abstract}
The competition for glucose as a growth-limiting substrate between Candida albicans and a mixed community of oral bacteria was investigated. A chemostat was operated under glucose-limiting and glucose excess conditions at a dilution rate of $0.05 / h$. A mixed population of oral bacteria was established and after a steady state had been reached the chemostat was inoculated with $C$. albicans. Seven bacterial species Streptococcus sanguis, S. sobrinus, S. mitis, Lactobacillus casei, Veillonella dispar, Eubacterium saburreum and Fusobacterium nucleatum - were able to establish stable populations under glucose-limiting conditions. The yeast was unable to grow with the bacteria under glucose limitation. Only three bacterial species, $S$. sobrinus, $L$. casei and $E$. saburreum, became established under glucose-excess conditions. $C$. albicans was also able to become established in the glucose-excess chemostat and could grow and maintain a steady state in a mixed culture with these organisms. $L$. casei, $S$. mitis and $S$. sobrinus had faster glucose consumption rates than $C$. albicans. All the bacteria, except for $F$. nucleatum, had maximum specific growth rates higher than $C$. albicans. The results suggest that glucose may act as a growth-limiting substrate for $C$. albicans in the establishment and growth of the yeast in a mixed community of oral bacteria.
\end{abstract}

\section{Introduction}

Oral candidosis is one of the most common fungal infections in man and is usually caused by the yeast Candida albicans. This micro-organism is a member of the commensal oral microbiota and occurs in $30-40 \%$ of clinically healthy mouths [1]. However, under certain conditions it can act as an opportunist pathogen and may cause several forms of oral candidosis. In the acute form, it may cause severe candidosis in AIDS patients and in patients who receive immunosuppressive drugs, chemotherapy or radiotherapy. In the chronic form, it causes oral discomfort [2].

Many factors can predispose individuals to oral candidosis. Some are mechanical, such as ill-fitting dentures. Some are related to the underlying disease status of the individual, while others are short-term, such as courses of antibiotic therapy [3]. Antibiotic treatment alters the composition of the endogenous microbiota, which then leads to overgrowth of the yeast

Received 16 March 1999; revised version received 6 Dec. 1999; accepted 8 Jan. 2000.

Corresponding author: Dr NJ Basson (e-mail:njb1@maties. sun.ac.za).
$[2,4]$. In theory, most antibacterial antibiotics possess the ability to eliminate bacteria that normally compete with the yeast for nutrients. Under these conditions, the yeast is able to multiply more readily and its overgrowth may then lead to infection [2].

Glucose is a highly utilisable substrate for C. albicans, both in culture media [5] and in human saliva [6], and it has been suggested that the competition for glucose between the yeast and bacteria plays a major role in preventing overgrowth of the yeast [7]. Candidosis occurs more often when there is high availability of glucose, as in persons with diabetes and in patients receiving total parenteral nutrition [8]. A carbohydraterich diet can also promote oral colonisation with Candida spp. [9, 10]. High carbohydrate levels in the gut tend to favour multiplication of the yeast and predispose to candidosis $[7,11]$. In-vitro studies have also shown that carbon limitation or excess plays an important role in controlling the establishment of organisms in mixed microbial populations [12-14]. Several in-vitro studies on the interactions of $C$. albicans with other micro-organisms have been published [2, 15-18]. However, most of the experiments have been done under simplified environmental conditions in which only one or two organisms were 
involved. This is not representative of the huge amount of different bacterial species that normally inhabit the oral cavity [19] and cannot be expected to reflect the interactions of a complex microbiota. One study was done on the interaction of $C$. albicans with a complex microbiota in a mixed culture and under continuousflow conditions [4]. However, this study was directed towards the ecology of the large intestine and used organisms totally different to those found in the oral cavity. Furthermore, the results of these experiments conflict quite markedly. For example, Lactobacillus spp. have been claimed both to enhance [15] and to inhibit [16] the growth of C. albicans. Liljemark and Gibbons [17] were able to suppress growth of $C$. albicans in germ-free mice contaminated with Streptococcus salivarius and S. mitior. On the other hand, invitro experiments could not demonstrate any interaction between S. salivarius and C. albicans [18].

Although Cormane and Goslings [7] studied the influence of glucose on the growth of $C$. albicans in vitro, they were unable to clarify which mechanism was responsible for their observed growth inhibition of $C$. albicans. Nevertheless, they observed that the growth of the yeast in the absence and the presence of bacteria, and its rate of inhibition in mixed cultures, were markedly influenced by the concentration of glucose.

In the light of the possible role of competition for glucose amongst populations in maintaining candidal homeostasis in the oral cavity, it was decided to investigate the competition for glucose between $C$. albicans and a mixed community of oral bacteria. This would be difficult to perform in vivo because of the different parameters in the oral cavity that could influence the growth of the organisms and which are uncontrollable in vivo. It has been shown that the chemostat can produce stable communities of oral bacteria that are reproducible in their microbial composition and biochemical activity [12, 20-21]. A chemostat also has the advantage that it can be used as an environmentally-related laboratory model that can be used to investigate cause-and-effect relationships by changes in a single parameter [21]. Therefore, the present study used the chemostat to investigate the effect of glucose limitation and excess on the establishment of $C$. albicans in a mixed community of oral bacteria under conditions related to the oral environment.

\section{Materials and methods}

\section{Growth conditions}

A BioFlo model C32 chemostat (New Brunswick Scientific, Edison, NJ, USA) was operated at a dilution rate of $0.05 / \mathrm{h}$, a temperature of $37^{\circ} \mathrm{C}$ and a working volume of $600 \mathrm{ml}$ under a gas phase of $\mathrm{CO}_{2} 5 \%+\mathrm{N}_{2}$ $95 \%(\mathrm{v} / \mathrm{v})$. The gas was bubbled into the medium through a sparge tube at a gas flow rate of $50 \mathrm{ml} / \mathrm{min}$.
The $\mathrm{pH}$ was maintained at $6.8 \pm 0.1$ by the automatic addition of $2 \mathrm{M} \mathrm{NaOH}$. The growth medium contained (/L of distilled water) proteose peptone (Oxoid) $5 \mathrm{~g}$, tryptone (Oxoid) $5 \mathrm{~g}$, LabLemco powder (Oxoid) $1 \mathrm{~g}$, yeast extract (Oxoid) $2 \mathrm{~g}$, cysteine hydrochloride (Merck, Darmstadt, Germany) $5 \mathrm{~g}, \mathrm{NaCl}$ (Merck) $5 \mathrm{~g}$, haemin (Sigma) $5 \mathrm{mg}$, menadione (Sigma) $1 \mathrm{mg}$, disodium hydrogen phosphate dodecahydrate (Merck) $14.8 \mathrm{~g}$, potassium di-hydrogen phosphate (Merck) $1.2 \mathrm{~g}$. The medium was supplemented with $28 \mathrm{~mm}$ glucose (BDH, Poole) to achieve glucose limitation. To obtain glucose-excess conditions, the medium was supplemented with $170 \mathrm{~mm}$ glucose (BDH). The medium and the glucose were autoclaved separately and the glucose was added aseptically after sterilisation.

\section{Bacterial strains}

The organisms were chosen for their known ability to become established in mixed culture in a chemostat [20]. The bacterial strains were obtained from the National Collection of Type Cultures (NCTC; Colindale Avenue, London) and the yeast was obtained from the National Collection of Pathogenic Fungi (NCPF; Colindale) The strains were: S. sanguis NCTC 10904, S. sobrinus NCTC 10921, S. mitis NCTC 10712, Lactobacillus casei NCTC 10302, Veillonella dispar (parvula) NCTC 11463 and Fusobacterium nucleatum ATCC 25586. The yeast was C. albicans strain NCPF 3118. The Eubacterium saburreum strain (B6I8) was isolated from a chemostat culture in this laboratory in a previous study [20].

\section{Chemostat inoculation}

Each organism was grown separately in anaerobic batch cultures in the chemostat growth medium for $12 \mathrm{~h}$. Then, $10 \mathrm{ml}$ of each culture (except the yeast) were inoculated into the chemostat. Approximately $300 \mathrm{ml}$ (half the working volume) of culture medium was pumped into the growth vessel to control the $\mathrm{pH}$ and temperature. The chemostat was re-inoculated on two subsequent occasions to establish all strains. Before each re-inoculation, a 100-ml volume of culture was removed. After a steady state had been reached, the chemostat was inoculated with $10 \mathrm{ml}$ of a 12-h culture of $C$. albicans grown in the same medium. Reinoculation with the yeast was performed on two subsequent occasions when it was noticed that the yeast was washed from the chemostat.

\section{Viable counts of the microbial community}

At the time of inoculation with the yeast and also at the termination of the experiment, viable counts of the chemostat communities were made. One-ml samples were removed from the growth vessel, dispersed, serially diluted in reduced transport fluid (RTF) [22] and plated on selective media. The media used were 
TYC medium [23] for the identification of the streptococci, Rogosa SL Agar (Difco) for lactobacilli, horse blood 5\% agar (Blood Agar Base No. 2, Oxoid) supplemented with haemin (Sigma) $5 \mathrm{mg} / \mathrm{L}$ and menadione (Sigma) $1 \mathrm{mg} / \mathrm{L}$ for the estimation of the total count and for enumeration of E. saburreum, and blood agar supplemented with vancomycin (Sigma) $2.5 \mu \mathrm{g} / \mathrm{ml}$ for enumeration of the gram-negative bacteria. All media were incubated anaerobically for 5 days in an atmosphere of $\mathrm{CO}_{2} 10 \%+\mathrm{H}_{2} 10 \%+\mathrm{N}_{2}$ $80 \%(\mathrm{v} / \mathrm{v})$. After inoculation with $C$. albicans, yeast counts were performed daily to monitor growth. A sample was removed from the chemostat and $1 \mathrm{ml}$ of this sample was dispersed, serially diluted in RTF and plated on Sabouraud Agar (Oxoid). The plates were incubated aerobically for $24 \mathrm{~h}$ at $37^{\circ} \mathrm{C}$ and the yeast colonies were counted.

\section{Measurement of the maximum specific growth rates of the microbial species}

The maximum specific growth rate of each organism was measured by growing each in pure batch culture in the chemostat under the same growth conditions used in the continuous culture experiments. The chemostat was loaded with $600 \mathrm{ml}$ of medium supplemented with $28 \mathrm{mM}$ glucose and brought to $37^{\circ} \mathrm{C}$. The apparatus was inoculated with $10 \mathrm{ml}$ of a 12-h culture and growth was monitored for optical density while being stirred as a batch culture. Cell dry weights were determined by taking duplicate 5-ml samples of killed culture (formalin $10 \%$ by volume), centrifuging, washing the cells once in distilled water and drying the washed deposit of cells at $110^{\circ} \mathrm{C}$ for 2 days. The maximum specific growth rate $\left(\mu_{\mathrm{m}}\right)$ of each organism was obtained by plotting the natural logarithm of the cell mass during the exponential growth phase against time, the best straight line being fitted by the method of least squares. The value of $\mu_{\mathrm{m}}$ was obtained by determining the slope of the straight line.

\section{Measurement of glucose consumption rates of the microbial species}

The glucose consumption rate of each organism was measured by growing the organisms in pure culture in the chemostat under the same growth conditions used in the mixed culture experiments. The chemostat was loaded with $600 \mathrm{ml}$ of medium supplemented with $28 \mathrm{mM}$ glucose and brought to $37^{\circ} \mathrm{C}$. The apparatus was inoculated with $10 \mathrm{ml}$ of a 12-h culture and growth was monitored for optical density while being stirred at a dilution rate (D) of $0.05 / \mathrm{h}$. Cell dry weights were determined by taking duplicate 5-ml samples of killed culture (formalin $10 \%$ by volume within $15 \mathrm{~s}$ ), centrifuging, washing the cells once in distilled water and drying the washed deposit of cells at $110^{\circ} \mathrm{C}$ for 2 days. The residual glucose concentration of the supernate was determined by the method described by Kingsley and Getchell [24]. The rate of glucose consumption was calculated from the equation of Herbert and Kornberg [25]:

$$
q_{s}=D\left(S_{0}-S\right) x
$$

where $q_{s}=$ the amount of glucose utilised (mg glucose/ mg dry mass of cells $/ \mathrm{h}), \mathrm{D}=$ the dilution rate $(/ \mathrm{h})$, $S_{0}=$ the glucose concentration in the inflowing medium $(\mathrm{mg} / \mathrm{ml}), S=$ the residual glucose concentration in the culture $(\mathrm{mg} / \mathrm{ml})$ and $x=$ dry mass of cells $(\mathrm{mg} / \mathrm{ml})$.

\section{Calculation of the theoretical washout rate}

The theoretical washout rate and the rate of loss of $C$. albicans from the chemostat were calculated from the equation

$$
\log _{\mathrm{e}} x_{t}=\log _{\mathrm{e}} x_{0}-D t
$$

where $x_{t}$ is the number of particles after time $t, x_{0}$ is the initial number of particles and $D$ is the dilution rate [26].

All the experiments in this study were repeated three times and all values in each experiment were obtained in duplicate.

\section{Results}

\section{Growth of bacterial species}

The microbial composition of the cultures after 10 volume changes (10 generations) is shown in Table 1 . The seven bacterial species which were inoculated into the glucose-limited chemostat all became established. A total population level of $\log _{10} 10.4$ (SD 2.1) $\mathrm{cfu} / \mathrm{ml}$ (total anaerobic count) was reached. $S$. sanguis and $S$. sobrinus dominated the culture. The asaccharolytic species $V$. dispar occurred at comparatively high counts while $L$. casei had the lowest count.

The glucose concentration of the growth medium (excess glucose) affected the microbial composition of the steady state communities. In contrast to the glucose-limited chemostat, only three of the seven bacterial species inoculated into the glucose-excess chemostat became established and reached a steady state - L. casei, S. sobrinus and E. saburreum (Table 1). A total population level of $\log _{10} 10.5$ (SD 0.5) cfu/ $\mathrm{ml}$ was reached. Both L. casei and S. sobrinus cell counts were higher than in the glucose-limited cultures and $S$. sanguis was replaced by $S$. sobrinus as the dominant species.

\section{Growth of C. albicans}

C. albicans was unable to establish and compete for a niche in the glucose-limited chemostat. Directly after inoculation the yeast counts were $\log _{10} 4.2$ (SD 0.2) $\mathrm{cfu} / \mathrm{ml}$. However, immediately after inoculation their numbers started to decline (Fig. 1). After 4 days the yeast cell counts were below the detection level of 
Table 1. The composition of the steady-state bacterial communities under conditions of glucose limitation and excess, the maximum specific growth rates $\left(\mu_{\mathrm{m}}\right)$ and the glucose consumption rate $\left(q_{s}\right)$ of the microbial species at $\mathrm{D}=$ $0.05 / \mathrm{h}$

\begin{tabular}{|c|c|c|c|c|}
\hline \multirow[b]{2}{*}{ Species } & \multicolumn{2}{|c|}{ Mean $\log _{10} \mathrm{cfu} / \mathrm{ml}(\mathrm{n}=6)$ under } & \multirow{2}{*}{$\begin{array}{l}\mu_{\mathrm{m}} \\
(/ \mathrm{h})\end{array}$} & \multirow{2}{*}{$\begin{array}{c}q_{s} \\
\text { (mg glucose/ } \\
\text { mg dry cells } / \mathrm{h} \text { ) }\end{array}$} \\
\hline & glucose limitation & glucose excess & & \\
\hline S. sanguis & 9.2 & ND & 0.514 & 4.9 \\
\hline S. sobrinus & 8.8 & 10 & 0.610 & 2.7 \\
\hline S. mitis & 6.1 & ND & 0.232 & 3.8 \\
\hline L. casei & 5.0 & 9.7 & 0.303 & 3.2 \\
\hline V. dispar* & 8.1 & ND & 0.355 & 0.0 \\
\hline E. saburreum* ${ }^{*}$ & 6.1 & 4.4 & 0.143 & 0.0 \\
\hline F. nucleatum* & 5.2 & ND & 0.153 & 0.16 \\
\hline C. albicans & ND & 2.9 & 0.197 & 1.5 \\
\hline Total population & $10.4(\mathrm{SD} 2.1)$ & $10.5(\mathrm{SD} 0.5)$ & $\ldots$ & $\ldots$ \\
\hline
\end{tabular}

$\mathrm{ND}$, not detected.

*Asaccharolytic species.

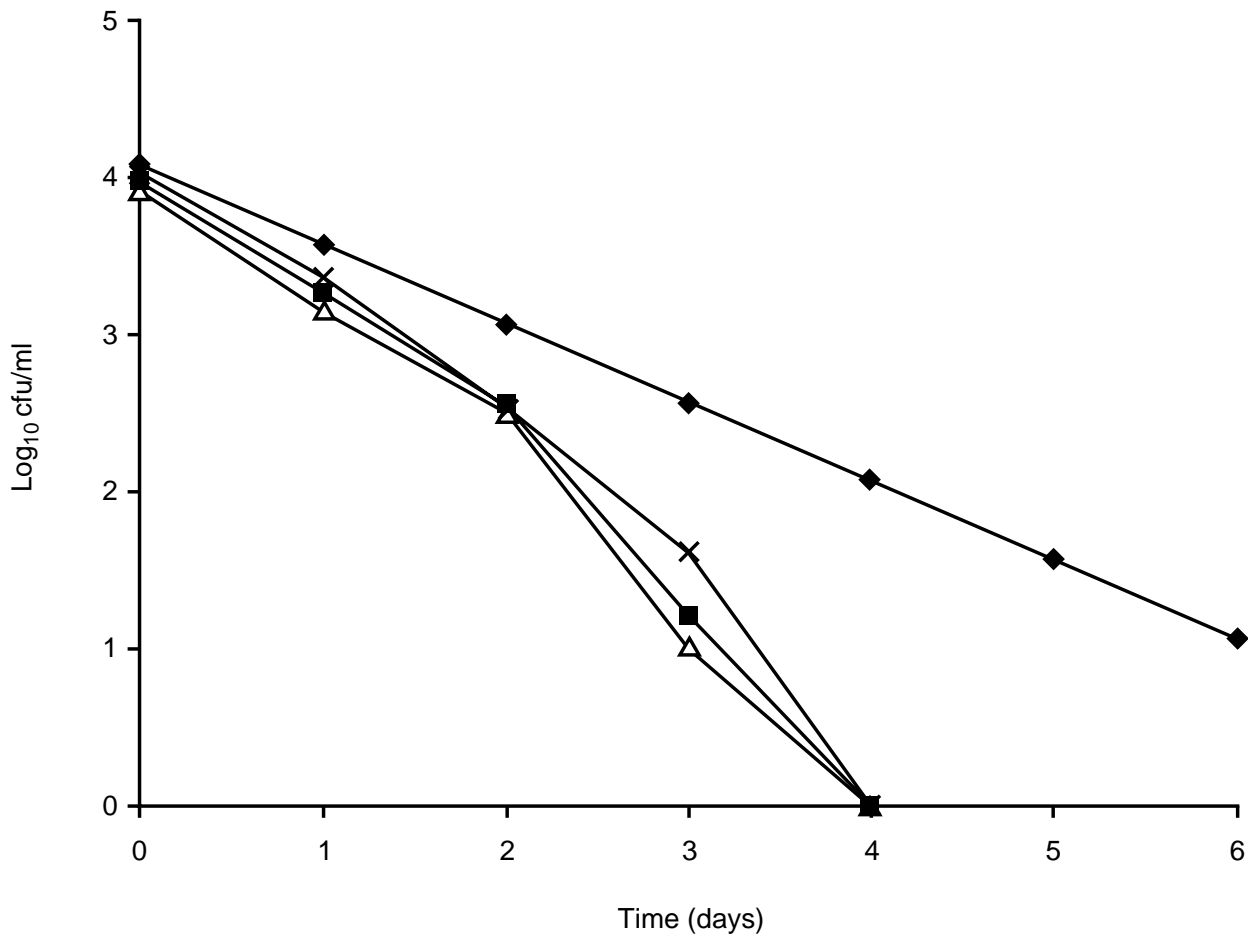

Fig. 1. The washout rate of an inert particle $(\diamond)$ and the loss of $C$. albicans cells under glucose-limiting conditions (experiments $1, \mathbf{\square} ; 2, \triangle ; 3, \times$ ).

$10 \mathrm{cfu} / \mathrm{ml}$. The yeast cells were lost at a mean rate of $0.038 / \mathrm{h}$. This was faster than the theoretical washout rate of $0.02 / \mathrm{h}$. There was no change in the bacterial composition of the chemostat culture after inoculation with the yeast.

On the other hand, C. albicans was able to become established and grow to a steady state in the glucoseexcess chemostat. During the first 2 days after inoculation, the yeast cell counts declined at a mean rate of $0.02 / \mathrm{h}$, equal to the theoretical washout rate. However, after 2 days the yeast growth rate stabilised at the dilution rate and maintained a steady state with a mean yeast count of $\log _{10} 2.9$ (SD 0.6) cfu/ml (Fig. 2).
As with the glucose-limited culture, no change in the bacterial composition occurred after inoculation with the yeast.

\section{Growth rates and substrate utilisation of the species}

The maximum specific growth rates of the organisms that were able to utilise glucose as carbon substrate ranged from $0.197 / \mathrm{h}$ to $0.610 / \mathrm{h}$ (Table 1 ). Of these organisms, $C$. albicans had the lowest maximum specific growth rate and $S$. sobrinus had the highest maximum specific growth rate. 


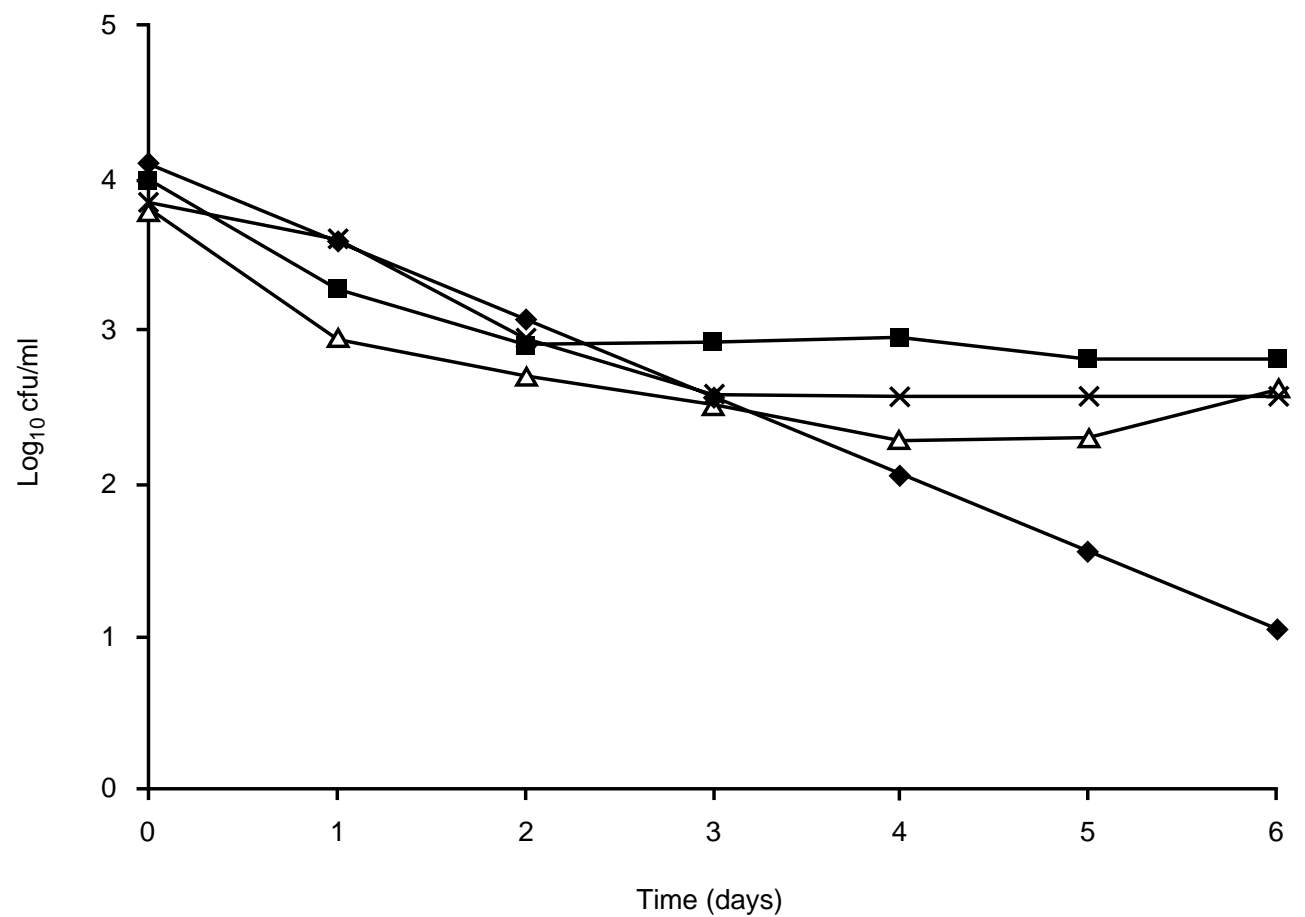

Fig. 2. The washout rate of an inert particle $(\bullet)$ and the growth of $C$. albicans under glucose-excess conditions (experiments $1, \mathbf{\square} ; 2, \triangle ; 3, \times)$.

Glucose did not act as a growth-limiting substrate for E. saburreum, F. nucleatum or $V$. dispar.

\section{Discussion}

In the glucose-limited chemostat, the experimental conditions were as follows: the dilution rate and hence the growth rate was constant, the culture was in a steady state, growth was limited by the deficiency of a single nutrient and the culture was perfectly mixed. Chemostat theory predicts that under these conditions, unless microbial interactions or mixed substrate utilisation occurs, a single bacterial population will competitively displace all others if a culture is inoculated with a mixture of organisms [27-30]. In the present study, a mixed microbial population comprising seven bacterial species was able to become established and maintain a steady state in the glucoselimited chemostat culture. This indicates that the populations that established themselves were not all dependent on glucose as carbon substrate, but made use of mixed substrate utilisation to develop into a complex community. This is in accordance with the results of McKee et al. [21]. The mixed substrate utilisation could be due to the interaction between primary feeders (those that use substrates present in the original growth medium) and secondary feeders (those that use metabolic by-products) [27]. It could also be related to the ability of some of the populations to avoid direct competition for the overall growth-limiting nutrient (glucose) of the community by using amino acids for their growth and energy requirements. For example, Veillonella spp. use lactate produced by other organ- isms [31]. Veillonella spp. have also been found to be associated with E. saburreum [32]. The co-existence of $S$. sanguis with other oral bacteria in glucose-limited chemostat cultures can be explained by the utilisation of arginine by this organism as a source of energy when glucose is unavailable $[33,34]$. F. nucleatum also has the ability to use amino acids as carbon and energy supplies [35].

The bacterial composition of the community was markedly influenced by excess glucose concentration. The glucose-excess chemostat had a lower species diversity. Four of the seven bacterial species in the inoculum were unable to colonise the chemostat, even after repeated inoculations. A lower species diversity in the presence of excess glucose was also observed by Marsh et al. [12] and McKee et al. [21]. This could be ascribed to a shortage of nitrogen supply in the form of a limitation of certain amino acids under the glucoseexcess conditions. McKee et al. [21] found that at least three amino acids were depleted from the culture medium under conditions of glucose excess, suggesting that competition for amino acids is an important factor in the establishment of some oral populations. The four bacteria that were unable to grow in the glucose-excess chemostat probably had to compete for a nitrogen source as a result of the depletion of amino acids. For example, as $V$. parvula needs amino acids for growth [36], it probably had to compete with L. casei, S. sobrinus and E. saburreum for essential amino acids. Similarly, the absence of $S$. sanguis, S. mitis and $F$. nucleatum in the glucose-excess culture could be due to a depletion of essential amino acids. On the other hand, the ability of $S$. sanguis and F. nucleatum to use 
amino acids as carbon and energy supplies [33, 35] could have enabled them to grow in the glucose-limited chemostat. L. casei, S. sobrinus and E. saburreum became established in both the glucose-limited and glucose-excess cultures, suggesting that they did not compete either for glucose or for the same amino acids.

The dilution rate of the chemostat was less than the maximum specific growth rate of all the organisms involved (Table 1). Therefore, no washout of any of the organisms as a result of a faster dilution rate could have occurred. Nevertheless, C. albicans was unable to colonise and compete for a niche in the mixed community of oral bacteria in the glucose-limited chemostat. In contrast, it could establish itself and grow in a steady state under glucose-excess conditions.

Except for the availability of glucose, all other growth conditions were favourable for the growth of the yeast in the glucose-limited chemostat. Although Candida spp. grow best under aerobic conditions, the yeast will grow under anaerobic conditions, but at reduced growth rates. Webster and Odds [37] found that the growth rate of the yeast will be reduced by $c .16 \%$ when grown anaerobically in an atmosphere containing $\mathrm{CO}_{2} \quad 5 \%$. With an aerobic maximum growth rate of $0.237 / \mathrm{h}$ in the same chemostat growth medium [20], a reduction in growth rate of $16 \%$ would give a growth rate of $c$. $0.198 / \mathrm{h}$. This was the observed growth rate of the yeast in this study, which was much faster than the dilution rate of the chemostat.

A number of interactions [27, 29] could be responsible for the inability of the yeast to establish in the glucoselimited chemostat. Excretion of metabolic by-products can easily give rise to population interactions additional to competition for nutrients. However, no antifungal substance was produced by the bacterial species when tested individually against the yeast (no mention of any antifungal substance, produced by the oral bacteria, could be found in previous reports). Furthermore, when the glucose-limited chemostat effluent was filtersterilised and supplemented with glucose, the yeast could grow in this medium. The latter finding, and the fact that the yeast could become established in the glucose excess chemostat, further indicate that no autoinhibitory substance was produced. In the absence of protozoa, the effects of predation can be excluded. Parasitism such as a viral element similar to a bacteriophage is possible but unlikely, especially in view of the fact that the yeast was able to grow in the filter-sterilised effluent after the addition of glucose. This suggests that the yeast could not establish in the glucose-limited chemostat because it could not compete with the bacteria for the limited available glucose. Starvation of the yeast cells as a result of the shortage of a carbon source could possibly explain why a death rate of $0.018 / \mathrm{h}(0.038-0.020 / \mathrm{h})$ was observed.

If no other interactions between populations occur, the outcome of competition under single substrate limitation is dependent on the actual specific growth rates and substrate affinity of the organisms involved [29]. The dilution rate of the chemostat was fixed at $\mathrm{D}=0.05 / \mathrm{h}$, which was less than the maximum specific growth rate of all the organisms (Table 1). Therefore, the substrate affinity of the different organisms could be a determining factor in the final outcome of the competition. The yeast would not be able to compete against the bacteria - L. casei, S. mitis and S. sobrinus - with faster glucose consumption rates. However, under conditions of glucose excess, the bacterial competition as a result of the faster glucose consumption rates would be eliminated and enough glucose would be available for the normal metabolism of the yeast, while the dilution rate of $0.05 / \mathrm{h}$ would be slow enough to prevent the yeast from being washed out.

Previous studies have shown that the chemostat can produce stable and reproducible communities of oral bacteria under conditions relevant to those found in the oral cavity $[12,20,21]$. The dilution rate of $0.05 / \mathrm{h}$, the temperature of $37^{\circ} \mathrm{C}$ and the gas phase of $\mathrm{CO}_{2} 5 \%+$ $\mathrm{N}_{2} 95 \%$ were chosen to simulate oral conditions. The particular species were chosen because of their known ability to become established and maintain a steady state under these conditions [20]. However, it must be emphasised that the chemostat cannot be used to simulate the oral cavity. It can only be used as an environmentally related model with which to control the large number of environmental parameters which would make an in-vivo study of this nature very difficult. Therefore, the results cannot be directly extrapolated to the oral cavity but the present study has demonstrated that the availability of glucose could act as a growth-limiting substrate for $C$. albicans when the yeast competes for a niche in a mixed microbial community under these particular environmental conditions. It also shows that L. casei, S. mitis and $S$. sobrinus might play a role in this respect.

In 1963, Cormane and Goslings [7] speculated on the importance of glucose for the growth of C. albicans in the oral cavity and suggested that the competition for glucose between bacteria and the yeast plays a major role in the survival and growth of the yeast. The importance of glucose was also shown by the fact that the yeast can grow only in glucose-supplemented saliva and not in saliva alone [6]. The results of the present study emphasise the possible role of glucose in the homeostasis of the yeast in a mixed microbial habitat. Clearly, more research is needed to clarify the role of glucose and other parameters involved. Future studies are under way in which this system is being used to study the effect of other parameters of oral significance on the homeostasis of $C$. albicans in the oral cavity.

This investigation was part of a study approved for the degree of $\mathrm{PhD}$ at the University of Stellenbosch. It was supported financially by the South African Medical Research Council. 


\section{References}

1. Arendorf TM, Walker DM. The prevalence and intra-oral distribution of Candida albicans in man. Arch Oral Biol 1980; 25: $1-10$.

2. Odds FC. Candida and candidosis, 2nd edn. London, Bailliere Tindall. 1988: 104-107.

3. Samaranayake LP. Host factors and oral candidosis. In: Samaranayake LP, MacFarlane TW (eds) Oral candidosis. London, Wright. 1990: 66-103.

4. Bernhardt H, Wellmer A, Zimmermann K, Knoke M. Growth of Candida albicans in normal and altered faecal flora in the model of continuous flow culture. Mycosis 1995; 38: 265-270.

5. Johnson SAM. Candida (Monilia) albicans. AMA Arch Dermatol Syphilol 1954; 70: 49-60.

6. Samaranayake LP, Hughes A, Weetman DA, MacFarlane TW. Growth and acid production of Candida species in human saliva supplemented with glucose. J Oral Pathol 1986; 15: $251-254$.

7. Cormane RH, Goslings WRO. Factors influencing the growth of Candida albicans (in vivo and in vitro studies). Sabouraudia 1963; 3: 52-63.

8. Bodey GP. Candidiasis in cancer patients. Am J Med 1984; 77: Suppl 4D: $13-19$.

9. Gentles JC, La Touche CJ. Yeasts as human and animal pathogens. In: Rose AH, Harrison JS (eds) The yeasts, vol 1. London, Academic Press. 1969: 107-182.

10. Samaranayake LP. Nutritional factors and oral candidosis. J Oral Pathol 1986; 15: 61-65.

11. Vargas SL, Patrick CC, Ayers GD, Hughes WT. Modulating effect of dietary carbohydrate supplementation on Candida albicans colonization and invasion in a neutropenic mouse model. Infect Immun 1993; 61: 619-626.

12. Marsh PD, Hunter JR, Bowden GH et al. The influence of growth rate and nutrient limitation on the microbial composition and biochemical properties of a mixed culture of oral bacteria grown in a chemostat. J Gen Microbiol 1983; 129: $755-770$.

13. Van der Hoeven JS, de Jong MH, Camp PJM, van den Kieboom CWA. Competition between oral Streptococcus species in the chemostat under alternating conditions of glucose limitation and excess. FEMS Microbiol Ecol 1985; 31: $373-379$.

14. Rogers AH, Zilm PS, Gully NJ. Influence of arginine on the coexistence of Streptococcus mutans and S. milleri in glucoselimited mixed continuous culture. Microb Ecol 1987; 14: 193-202.

15. Young G, Krasner RI, Yudofsky PL. Interactions of oral strains of Candida albicans and lactobacilli. J Bacteriol 1956; 72: 525-529.

16. Isenberg HD, Berkman JI, Carito SL. Factors leading to overt monilial disease. II Retardation of growth of Candida albicans by metabolic end products of intestinal bacteria. Antimicrob Agents Ann 1960; 10: 570-575.

17. Liljemark WF, Gibbons RJ. Suppression of Candida albicans by human oral streptococci in gnotobiotic mice. Infect Immun 1973; 8: 846-849.

18. de Miranda CM, van Wyk CW, Basson NJ. Growth interaction between Candida albicans and Streptococcus salivarius: in vitro and in vivo studies. $J$ Dent Assoc $S$ Afr 1992; 47: $253-256$.

19. Marsh P, Martin M. Oral microbiology, 3rd edn. London, Chapman \& Hall. 1992: 27-55.

20. Basson NJ, van Wyk CW. The establishment of a community of oral bacteria that controls the growth of Candida albicans in a chemostat. Oral Microbiol Immunol 1996; 11: 199-202.

21. McKee AS, McDermid AS, Ellwood DC, Marsh PD. The establishment of reproducible, complex communities of oral bacteria in the chemostat using defined inocula. $J \mathrm{Appl}$ Bacteriol 1985; 59: 263-275.

22. Syed SA, Loesche WJ. Survival of human dental plaque flora in various transport media. Appl Microbiol 1972; 24: 638-644.

23. De Stoppelaar JD, van Houte J, del Moor CE. The presence of dextran-forming bacteria, resembling Streptococcus bovis and Streptococcus sanguis, in human dental plaque. Arch Oral Biol 1967; 12: 1199-1202.

24. Kingsley GR, Getchell G. Direct ultramicro glucose oxidase method for determination of glucose in biologic fluids. Clin Chem 1960; 6: 466-475.

25. Herbert D, Kornberg HL. Glucose transport as rate-limiting step in the growth of Escherichia coli on glucose. Biochem $J$ 1976; 156: 477-480.

26. Powell EO. Theory of the chemostat. Lab Pract 1965; 14: 1145-1149.

27. Fredrickson AG, Stephanopoulos G. Microbial competition Science 1981; 213: 972-979.

28. Harder W, Veldkamp H. Competition of marine psychrophilic bacteria at low temperatures. Antonie van Leeuwenhoek 1971; 37: $51-63$.

29. Veldkamp H, Jannasch HW. Mixed culture studies with the chemostat. J Appl Chem Biotechnol 1972; 22: 105-123.

30. Tempest DW. The continuous cultivation of micro-organisms. I. Theory of the chemostat. In: Norris JR, Ribbons DW (eds) Methods in microbiology, vol 2. London, Academic Press. 1970: 259-276.

31. Mikx FHM, Van der Hoeven JS. Symbiosis of Streptococcus mutans and Veillonella alcalescens in mixed continuous cultures. Arch Oral Biol 1975; 20: 407-410.

32. Mashimo PA, Murayama Y, Reynolds H, Mouton C, Ellison SA, Genco RJ. Eubacterium saburreum and Veillonella parvula: a symbiotic association of oral strains. J Periodontol 1981; 52: 374-379.

33. Carlsson J. Nutritional requirements of Streptococcus sanguis. Arch Oral Biol 1972; 17: 1327-1332.

34. Rogers AH, de Jong MH, Zilm PS, van der Hoeven JS. Estimation of growth parameters for some oral bacteria grown in continuous culture under glucose-limiting conditions. Infect Immun 1986; 52: 897-901.

35. Rogers AH, Zilm PS, Gully NJ, Pfennig AL, Marsh PD Aspects of the growth and metabolism of Fusobacterium nucleatum ATCC 10953 in continuous culture. Oral Microbiol Immunol 1991; 6: 250-255.

36. Delwiche EA, Pestka JJ, Tortorello ML. The Veillonellae: Gram-negative cocci with a unique physiology. Annu Rev Microbiol 1985; 39: 175-193.

37. Webster CE, Odds FC. Growth of pathogenic Candida isolates anaerobically and under elevated concentrations of $\mathrm{CO}_{2}$ in air. J Med Vet Mycol 1987; 25: 47-53. 